Eur. J. Clin. Chem. Clin. Biochem.

Vol. 29, 1991, pp. 57-66

(C) 1991 Walter de Gruyter \& Co. Berlin - New York

\title{
Determination of Digoxin in the Blood of Pregnant Women, Fetuses and Neonates before and during Anti-arrhythmic Therapy, Using Four Immunochemical Methods
}

\author{
By H. Schlebusch, S. v. Mende, U. Grünn, U. Gembruch, R. Bald and M. Hansmann \\ Centre for Obstetrics and Gynaecology, University of Bonn
}

(Received February 19/September 6, 1990)

Summary: Four immunochemical methods for digoxin assay were used to analyse control samples, 33 amniotic fluid samples, 57 samples from digitalis-treated, non-pregnant women, 90 pregnancy serum samples, and 72 samples of fetal or neonatal serum with or without digoxin therapy. One hundred and five samples were also submitted to ultrafiltration before analysis.

Three methods (RIA, TD, AMERLITE) showed practically the same precision, while the precision of the DELFIA was markedly inferior. In the analysis of serum samples from digoxin-treated, non-pregnant women, RIA and TD $_{x}$ gave practically the same values, whereas AMERLITE and DELFIA gave significantly higher values.

Pregnancy serum and fetal serum contain "digoxin-like immunoreactive factors", and the qualitative and quantitative effects of these interfering factors are different for each of the four methods. The greatest sensitivity to "digoxin-like immunoreactive factors" is shown by $\mathrm{TD}_{\mathrm{X}}$ and DELFIA, while the lowest interference by "digoxin-like immunoreactive factors" is found in the analysis of ultrafiltered samples, using the $\mathrm{TD}_{\mathrm{x}}$ method.

The composition of the "digoxin-like immunoreactive factors" in pregnancy serum and in fetal serum is altered by digoxin therapy, and these changes have different effects on the various analytical methods. The concentration of "digoxin-like immunoreactive factors" in the serum of fetuses receiving digoxin is markedly lower than that of healthy fetuses.

For the reliable monitoring of digoxin therapy in the maternal and fetal circulation, the blood samples must be submitted to ultrafiltration before analysis.

\section{Introduction}

Fetal tachyarrhythmia - supraventricular tachycardia and atrial flutter - in utero can lead to fetal congestive heart failure with the signs of non-immune hydrops, and to death of the fetus. The reliable prenatal diagnosis of this condition is nowdays possible by sonographic and echocardiographic investigation of the fetus. Transplacental treatment of the fetus by the administration of antiarrhythmic agents to the mother can lead to cardioversion of the tachyarrhythmia to a sinus rhythm with consecutive cardiac re- compensation (1-4). For this purpose, digitalis agents are preferred, but in most cases they must be combined with other antiarrthythmic drugs (4). When hydrops is absent or not very pronounced, this conventional transplacental therapy is almost always successful, provided the dose is sufficiently high. In the presence of a backward failure with pronounced hydrops, however, it is frequently unsuccessful (5).

Possible reasons for failure of the therapy are an altered responsiveness of the affected fetal heart and/ 
or a decreased placental transfer of the antiarrhythmic agents, due to disturbed placental diffusion during the period of fetal congestive heart failure (5-7). Decreased placental transfer of digoxin has been confirmed by determination of digoxin in the maternal and umbilical blood of hydropic newborn infants (7). Further, by repeated sampling of fetal blood (puncture of the umbilical vein is performed with sonographic monitoring), and simultaneous determination of digoxin in maternal and fetal blood, it has been shown that the placental transfer of digoxin is markedly decreased during tachyarrhythmia with hydrops, but that it becomes normal after cardioversion and cardiac recompensation (8).

In cases of tachycardia with hydrops refractory to antiarrhythmic treatment, in addition to performing transplacental therapy, it is therefore expedient to also inject antiarrhythmic agents into the fetus to achieve therapeutic concentrations in the fetal compartments. For this purpose, injections are made into the umbilical vein under sonographic guidance. Simultaneously, the fetal blood concentration of the antiarrhythmic agents is measured, on the one hand to monitor the therapy, and on the other hand to obtain urgently needed pharmacokinetic data (8).

Transplacental treatment with digitalis agents is also recommended and carried out for other fetal conditions involving congestive heart failure with hydrops, such as structural malformations, coccygeal teratoma, twin transfusion syndrome and parasitic twin (9). Placental transfer is also assumed to be deficient in these cases, a fact which we have already confirmed by fetal blood analysis (unpublished results). In all these cases, it is necessary to test the efficiency of intrauterine therapy by determining drug concentrations in the maternal and fetal circulation, especially since the high doses of digitalis can also eventually endanger the health of the mother.

The clinical chemical laboratory therefore requires a method for digoxin determination in single, emergency samples, which produces results as quickly as possible, and which is not subject to interference by, e. g. "digoxin-like immunoreactive factors (DLIF)".

"Digoxin-like immunoreactive factors" have been found in the blood of patients with liver and kidney illnesses, in pregnant women and newborn infants, and in amniotic fluid, the reported concentrations showing a marked dependency on the determination method (10-14).

In the present work, the influence of "digoxin-like immunoreactive factors" on three non-radioactive immunochemical methods and a radioimmunoassay for digoxin were investigated, and a procedure for the elimination of "digoxin-like immunoreactive factors" was tested.

\section{Materials and Methods}

Samples

"Digoxin-like immunoreactive factors" concentrations were determined in serum samples from 50 healthy, pregnant women between the 16th and 40th week of pregnancy, in 20 umbilical sera from healthy, mature, newborn infants, and in 32 fetal blood samples from fetuses between the 18 th and 34 th week of pregnancy. Fetal blood samples were obtained by puncture of the fetal umbilical vein with sonographic monitoring (15), and 33 amniotic fluid samples were obtained between the 24th and 35 th week of pregnancy by transabdominal puncture. All serum samples were also submitted to ultrafiltration.

For the comparison of methods, 57 sera from non-pregnant women under digoxin therapy were selected, and 35 of these were also submitted to ultrafiltration.

Additionally, 40 serum samples from pregnant women treated for foetal tachyarrhythmia with digoxin were analysed. All samples were also subjected to ultrafiltration.

Finally, 30 blood samples were investigated from fetuses between the 25th and 36th week of pregnancy, who had been treated either by administration of digitalis preparations to the mother, or by direct injection of the drugs into the umbilical vein. In all samples, the digoxin concentration was determined with $T D_{x}$ before and after ultrafiltration. Owing to the limited sample volumes, it was possible to analyse only 20 samples with RIA, DELFIA and AMERLITE.

All sera were analysed within 6 hours of sampling, or stored at $-20^{\circ} \mathrm{C}$ until analysis.

\section{Controls}

For the determination of precision, 4 control samples were used, supplied by the "Deutsche Gesellschaft für Klinische Chemie".

\section{Methods}

The following analytical methods were used:

1. Fluorescence-polarization-immunoassay $\left(T_{\mathrm{x}}\right) ; \mathrm{TD}_{\mathrm{x}} \mathrm{Di}$ goxin II (Abbott Laboratories, Diagnostics Division, Chicago, USA).

2. Time-resolved fluoroimmunoassay (DELFIA); DELFIA Digoxin kit (Wallac Oy, Turku, Finland).

3. Enhanced luminescence immunoassay (AMERLITE);' AMERLITE-Digoxin-Assay (Amersham International plc, Little Chalfont, England).

4. Radio-immunoassay (RIA); Coat-A-Count Digoxin (Diagnostic Product Corporation, Los Angeles, USA).

All determinations were performed according to the instructions of the manufacturers.

\section{Ultrafiltration}

Based on the work of Graves (16) and Christenson (17), $500 \mu \mathrm{l}$ serum were pipetted into the sample reservoir of a filter (Centrifee Micropartition System, YMT-membrane, exclusion limit 
30000 Dalton, Amicon Division, Danvers, USA), and allowed to equilibrate at least $1 \mathrm{~h}$ at $4^{\circ} \mathrm{C}$. It was then centrifuged for $45 \mathrm{~min}$ at $+4^{\circ} \mathrm{C}$ and $1500 \mathrm{~g}$, using a $45^{\circ}$ fixed angle rotor. An aliquot $(200 \mu \mathrm{l})$ of the filtrate was diluted with $200 \mu \mathrm{l}$ sulphosalicylic acid (140 mmol/l in aqueous methanol, volume fraction 0.5 ) and analysed by fluorescence-polarization-immunoassay (TDX).

Contrary to the reports of Christenson (17), the protein-free ultrafiltrate could not be analysed without this dilution step.

\section{Statistics}

The minimum detection limit of the assays was calculated according to Borth (18). The within-run standard deviation was calculated from sample duplicates with concentrations below $0.8 \mathrm{nmol} / 1$ (19).

For the comparison of methods, the regression equations were calculated according to the procedure of Passing \& Bablok (20).

Mass concentrations can be calculated from the following relationship: $1 \mu \mathrm{g} / 1=1.28 \mathrm{nmol} / \mathrm{l}$.

\section{Results}

The data for precision in series and from day to day for the investigated methods are summarized in table 1. The minimum detection limit was determined as $0.06 \mathrm{nmol} / 1\left(\mathrm{TD}_{\mathrm{X}}\right), 0.11 \mathrm{nmol} / 1$ (DELFIA), 0.07 $\mathrm{nmol} / 1$ (AMERLITE), and $0.09 \mathrm{nmol} / \mathrm{l}$ (RIA).

Fifty serum samples from healthy, pregnant women not receiving digitalis therapy were investigated with 4 methods. In addition, the samples were submitted to ultrafiltration, then measured by $\mathrm{TD}_{\mathrm{x}}$; the results are listed in table 2.

Table 3 shows the results from 20 umbilical cord blood samples and 32 fetal blood samples without digoxin therapy. Since there was no significant difference between these two sub-groups, the respective data were combined.

Tab. 1. Precision of four methods for the determination of digoxin.

\begin{tabular}{|c|c|c|c|c|c|c|c|c|c|c|c|c|c|}
\hline & & \multicolumn{3}{|l|}{$\mathrm{TD}_{\mathrm{x}}$} & \multicolumn{3}{|c|}{ DELFIA } & \multicolumn{3}{|c|}{ AMERLITE } & \multicolumn{3}{|l|}{ RIA } \\
\hline & & $\overline{\mathbf{x}}$ & s & $\mathrm{CV} \%$ & $\overline{\mathbf{x}}$ & $\mathbf{s}$ & $\mathrm{CV} \%$ & $\overline{\bar{x}}$ & $\mathbf{s}$ & $\mathrm{CV} \%$ & $\overline{\bar{x}}$ & $\bar{s}$ & $\mathrm{CV} \%$ \\
\hline $\begin{array}{l}\text { Within assay } \\
(\mathrm{N}=20)\end{array}$ & $\begin{array}{l}\text { P1 } \\
\text { P2 }\end{array}$ & $\begin{array}{l}1.19 \\
2.64\end{array}$ & $\begin{array}{l}0.044 \\
0.048\end{array}$ & $\begin{array}{l}3.7 \\
1.8\end{array}$ & $\begin{array}{l}1.21 \\
3.20\end{array}$ & $\begin{array}{l}0.091 \\
0.151\end{array}$ & $\begin{array}{l}7.5 \\
4.7\end{array}$ & $\begin{array}{l}1.14 \\
2.94\end{array}$ & $\begin{array}{l}0.051 \\
0.091\end{array}$ & $\begin{array}{l}4.5 \\
3.1\end{array}$ & $\begin{array}{l}1.01 \\
2.62\end{array}$ & $\begin{array}{l}0.064 \\
0.055\end{array}$ & $\begin{array}{l}6.3 \\
2.1\end{array}$ \\
\hline $\begin{array}{l}\text { Between assays } \\
(\mathrm{N}=20)\end{array}$ & $\begin{array}{l}\text { P3 } \\
\text { P4 }\end{array}$ & $\begin{array}{l}1.04 \\
2.56\end{array}$ & $\begin{array}{l}0.067 \\
0.092\end{array}$ & $\begin{array}{l}6.6 \\
3.6\end{array}$ & $\begin{array}{l}1.54 \\
3.08\end{array}$ & $\begin{array}{l}0.222 \\
0.302\end{array}$ & $\begin{array}{r}14.4 \\
9.8\end{array}$ & $\begin{array}{l}1.14 \\
2.87\end{array}$ & $\begin{array}{l}0.068 \\
0.132\end{array}$ & $\begin{array}{l}6.0 \\
4.6\end{array}$ & $\begin{array}{l}0.96 \\
2.84\end{array}$ & $\begin{array}{l}0.084 \\
0.145\end{array}$ & $\begin{array}{l}8.7 \\
5.1\end{array}$ \\
\hline
\end{tabular}

Tab. 2. Concentration of digoxin-like immunoreactive factors (DLIF) in the serum of healthy pregnant women not receiving digoxin.

\begin{tabular}{lllccc}
\hline & TD & $\begin{array}{l}\text { TD } \\
\text { after } \\
\text { ultrafiltration }\end{array}$ & DELFIA & AMERLITE RIA \\
\hline Samples investigated & 50 & 50 & 50 & 50 & 50 \\
DLIF-positive samples & $50(100 \%)$ & $5(10 \%)$ & $21(42 \%)$ & $9(18 \%)$ & $11(22 \%)$ \\
$\begin{array}{l}\text { Median of DLIF in positive samples } \\
\text { (nmol/l) }\end{array}$ & 0.20 & 0.02 & 0.20 & 0.09 & 0.09 \\
$\begin{array}{l}\text { Range of DLIF in positive samples } \\
\text { (nmol/l) }\end{array}$ & $0.05-0.54$ & $0.01-0.07$ & $0.03-0.37$ & $0.05-0.14$ & $0.04-0.20$ \\
\hline
\end{tabular}

Tab. 3. Concentration of digoxin-like immunoreactive factors (DLIF) in fetal $(N=32)$ and in umbilical serum ( $N=20)$ from fetuses or newborn infants not receiving digoxin.

\begin{tabular}{llllcr}
\hline & TD & $\begin{array}{l}\text { TD } \\
\text { after } \\
\text { ultrafiltration }\end{array}$ & DELFIA & AMERLITE \\
\hline Samples investigated & 52 & 52 & 52 & 52 & 52 \\
DLIF-positive samples & $52(100 \%)$ & $14(27 \%)$ & $52(100 \%)$ & $51(98 \%)$ & 0.18 \\
$\begin{array}{l}\text { Median of DLIF in positive samples } \\
\text { (nmol/l) }\end{array}$ & 0.63 & 0.05 & 0.61 & 0.09 \\
$\begin{array}{l}\text { Range of DLIF in positive samples } \\
\text { (nmol/l) }\end{array}$ & $0.31-0.92$ & $0.01-0.09$ & $0.33-1.16$ & $0.05-0.52$ & $0.09-0.11$ \\
\hline
\end{tabular}


Tab. 4. Concentration of digoxin-like immunoreactive factors (DLIF) in amniotic fluid $(\mathrm{N}=33$ ) from healthy women not receiving digoxin.

\begin{tabular}{lllll}
\hline & TD & DELFIA & AMERLITE & RIA \\
\hline Samples investigated & 33 & 33 & 33 & 33 \\
$\begin{array}{l}\text { DLIF-positive samples } \\
\begin{array}{l}\text { Median of DLIF in positive samples } \\
\text { (nmol/l) }\end{array}\end{array}$ & $33(100 \%)$ & $33(100 \%)$ & $28(85 \%)$ & 0 \\
$\begin{array}{l}\text { Range of DLIF in positive samples } \\
\text { (nmol/l) }\end{array}$ & 0.32 & 0.19 & 0.14 & - \\
\hline
\end{tabular}
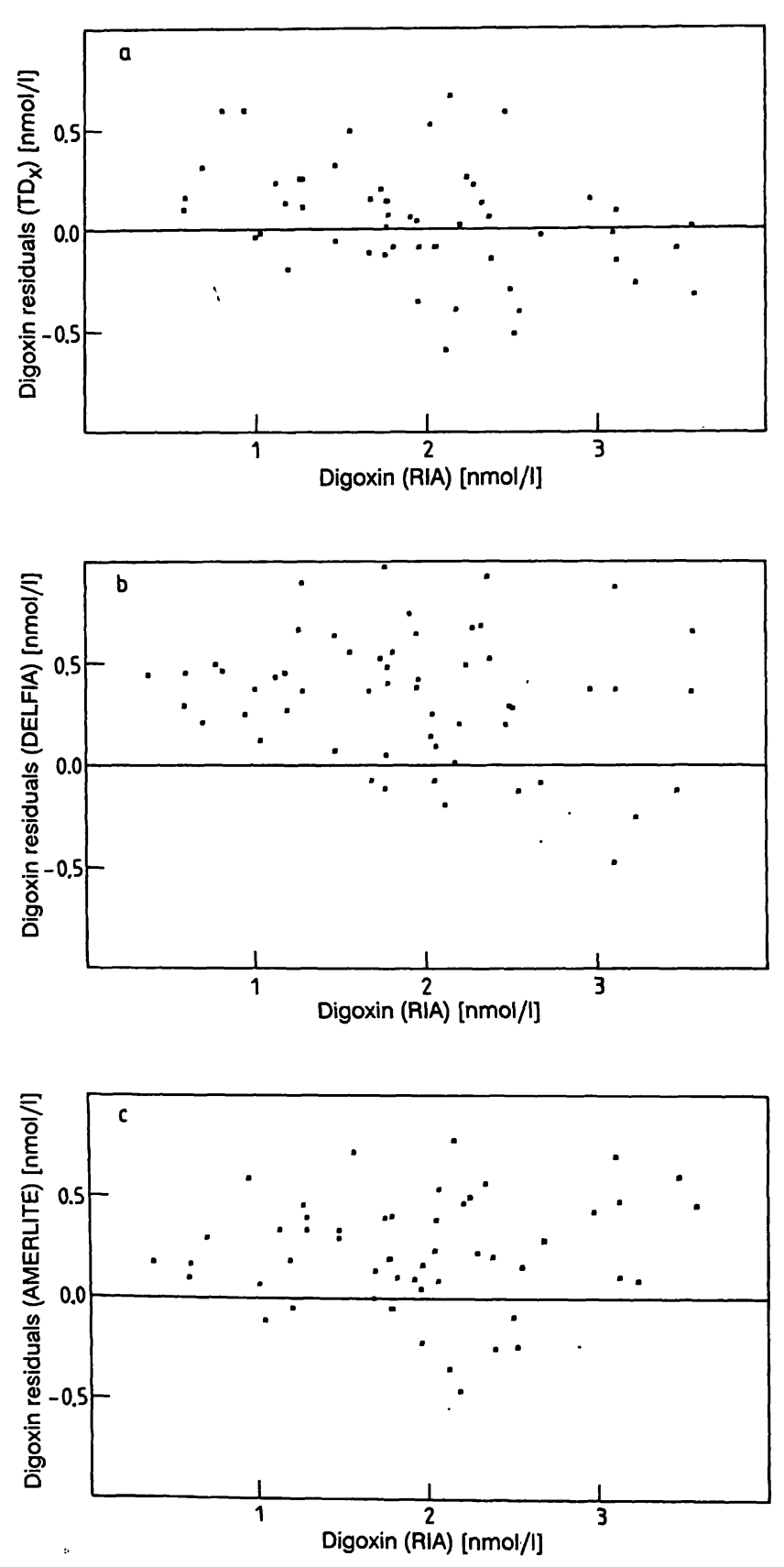

Fig. $1(a-c)$. Differences ( $y$-axis) between the analytical values obtained with $\mathrm{TD}_{\mathrm{x}}(\mathrm{a})$, DELFIA (b) or AMERLITE (c) and those obtained with RIA ( $x$-axis) in the serum of 57 digoxin-treated, non-pregnant women.
Table 4 contains the results of the analysis of 33 amniotic fluid samples from pregnant women not receiving digitalis therapy. Owing to the low protein content, ultrafiltration of amniotic fluid does not lead to a marked decrease of the concentration of "digoxin-like immunoreactive factors".

Figure $1(a-c)$ shows the results of the method comparison on 57 serum samples from non-pregnant women undergoing digoxin therapy. There is as yet no reference method for digoxin determination. How: ever, since the RIA used here is not influenced by "digoxin-like immunoreactive factors" $(13,21)$, or only slightly (22) (see also tables 2-4), it was used as the reference for present purposes. Figure 2 shows the effect of ultrafiltration.

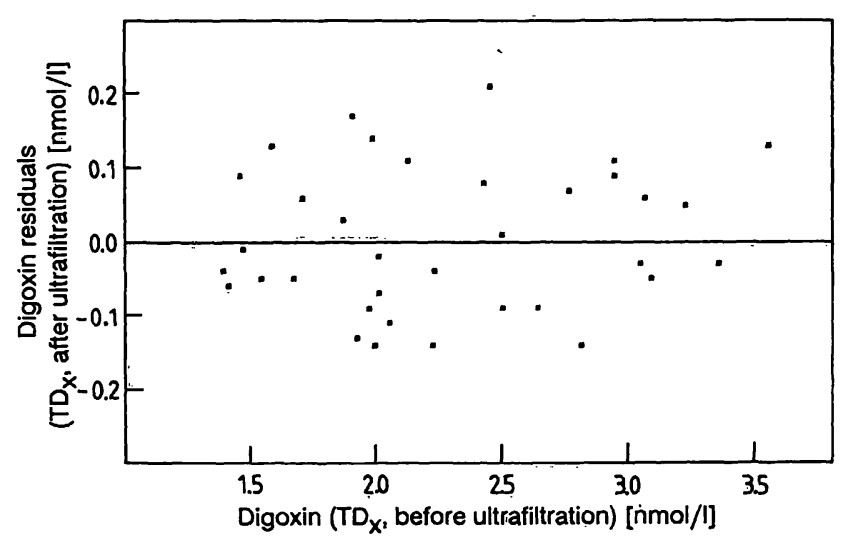

Fig. 2. Differences (y-axis) between the digoxin values measured with the $T D_{x}$ method after and before ultrafiltration ( $\mathrm{x}$-axis) in the serum of 35 digoxin-treated, nonpregnant women.

Figure $3(a-c)$ shows the results of the method comparison for 40 sera from pregnant women undergoing digoxin therapy. Figure 4 shows the results of the elimination of "digoxin-like immunoreactive factors" by ultracentrifugation. 

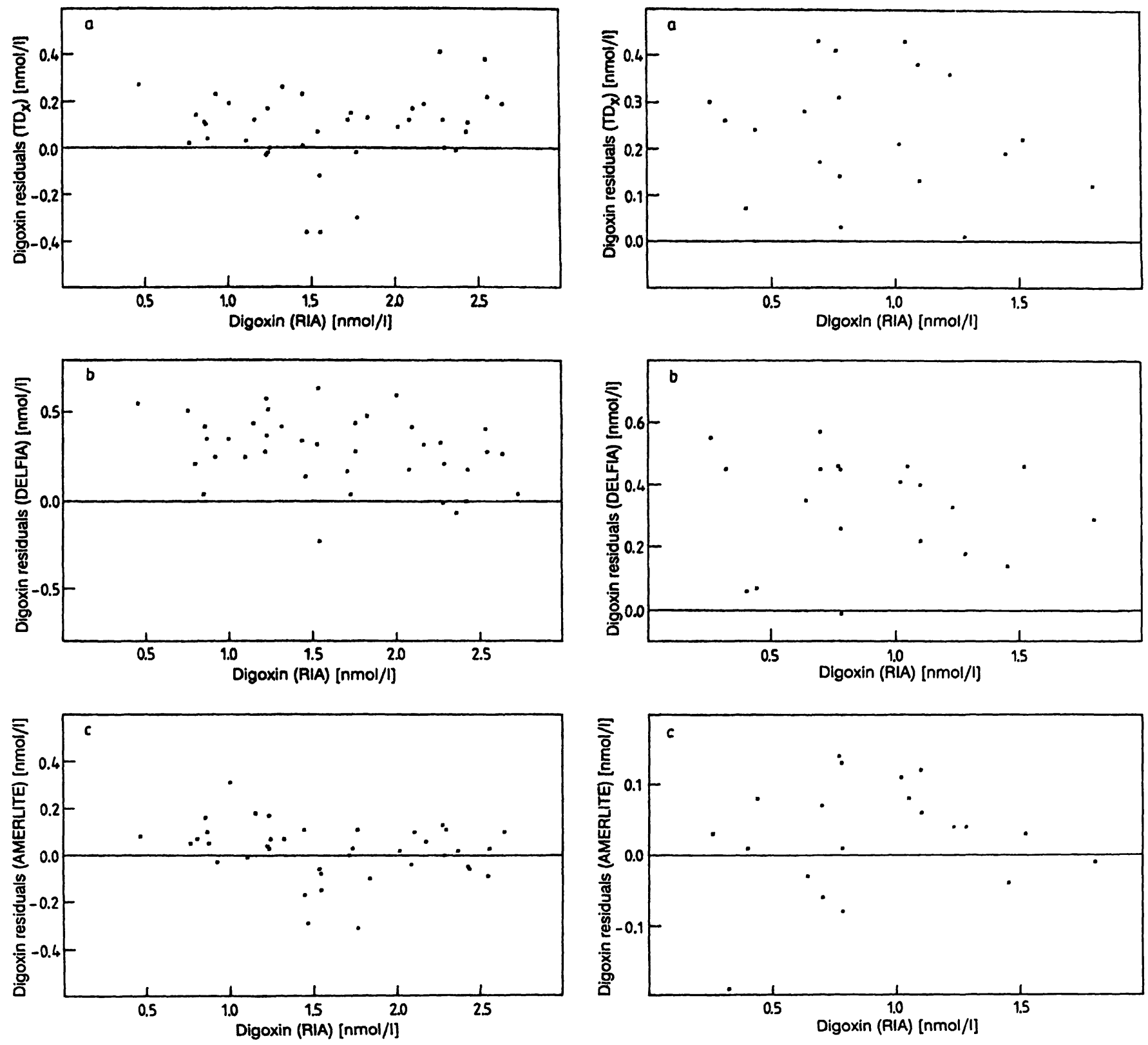

Fig. $3(a-c)$. Differences (y-axis) between the analytical values obtained with TD $(a)$, DELFIA (b) or AMERLITE (c) and those obtained with RIA (x-axis) in the serum of 40 digoxin-treated pregnant women.

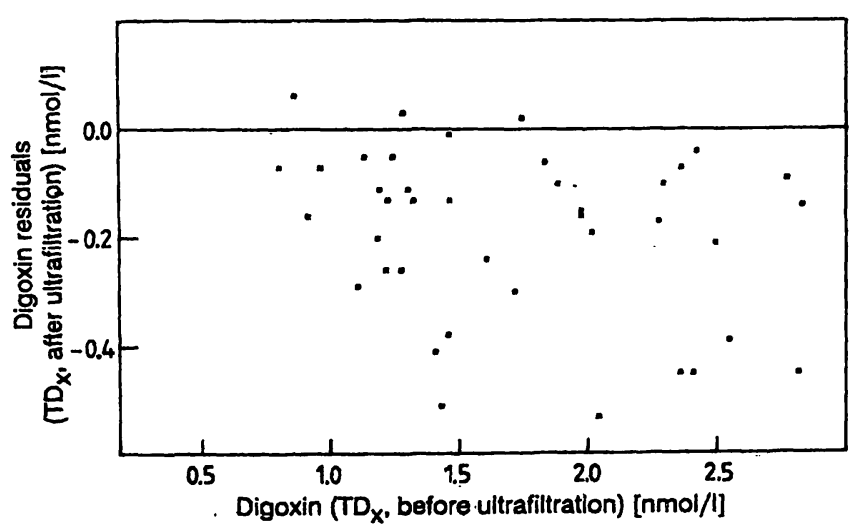

Fig. 4. Differences (y-axis) between the digoxin values measured with the TD method after and before ultrafiltration ( $x$-axis) in the serum of 40 digoxin-treated pregnant women.

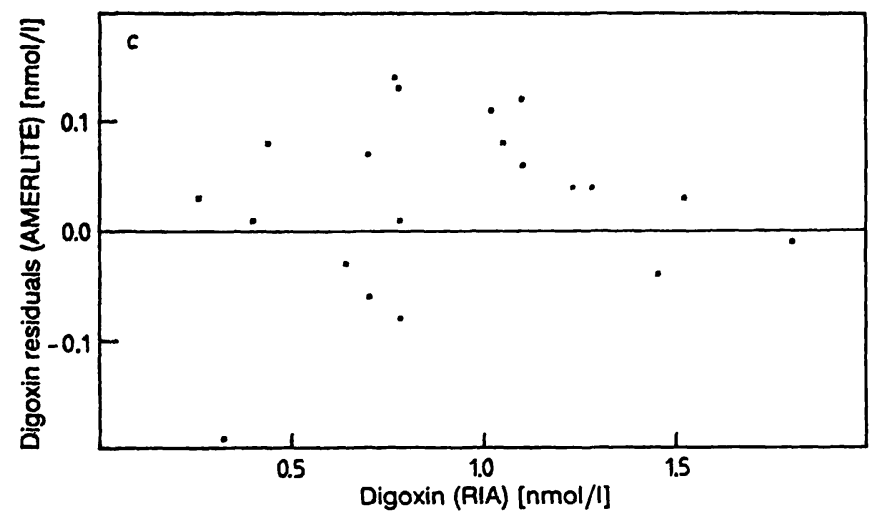

Fig. $5(a-c)$. Differences ( $y$-axis) between the analytical values obtained with TD $(a)$, DELFIA (b) or AMERLITE (c) and those obtained with RIA in the serum of 20 digoxin-treated fetuses.

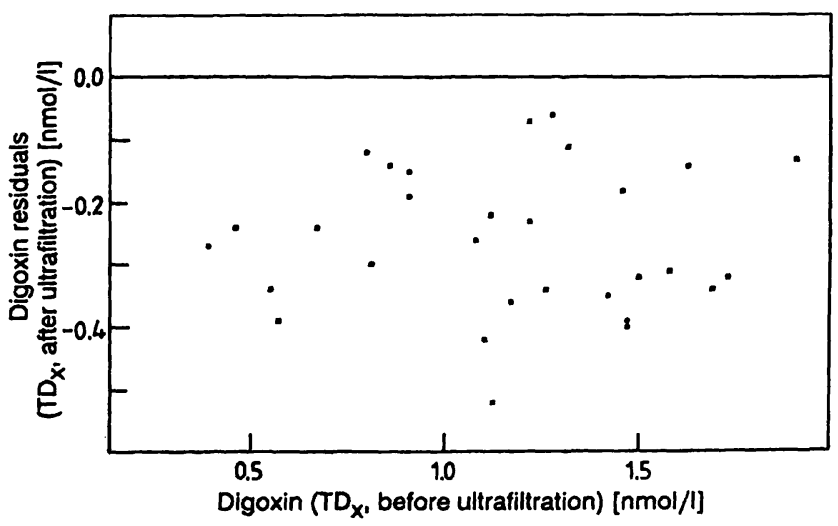

Fig. 6. Differences (y-axis) between the digoxin values measured with the TDx method after and before ultrafiltration (x-axis) in the serum of 30 digoxin-treated fetuses.

Eur. J. Clin. Chem. Clin. Biochem. / Vol. 29, 1991 / No. 1 
Tab. 5. Statistical evaluation of the comparison of the three non-radioactive methods for digoxin determination with the radioimmunoussay. $(a=$ point of intersection of the axis, $b=$ slope of the regression line; $r=$ correlation coefficient; $d=$ difference between the average values from the investigated method and the radioimmunoassay).

\begin{tabular}{|c|c|c|c|c|c|c|}
\hline Patient & Method & a & $b$ & $r^{\Delta}$ & & $d$ \\
\hline $\begin{array}{l}\text { Non pregnant } \\
\text { womcn with } \\
\text { digoxin therapy } \\
\mathrm{N}=57\end{array}$ & $\begin{array}{l}\text { TD }_{\mathbf{x}} \\
\text { DELFIA } \\
\text { AMERLITE }\end{array}$ & $\begin{array}{l}0.208^{*} \\
0.323^{*} \\
0.026\end{array}$ & $\begin{array}{l}0.923 \\
1.028 \\
1.105^{* *}\end{array}$ & $\begin{array}{l}0.930 \\
0.913 \\
0.943\end{array}$ & . & $\begin{array}{r}-0.09 \\
0.31^{* * *} \\
0.21^{* * *}\end{array}$ \\
\hline $\begin{array}{l}\text { Pregnant } \\
\text { women with } \\
\text { digoxin therapy } \\
\mathrm{N}=40\end{array}$ & $\begin{array}{l}\text { TD } \\
\text { DELFIA } \\
\text { AMERLITE }\end{array}$ & $\begin{array}{l}0.022 \\
0.417^{*} \\
0.080\end{array}$ & $\begin{array}{l}1.047 \\
0.942 \\
0.970\end{array}$ & $\begin{array}{l}0.967 \\
0.949 \\
0.979\end{array}$ & & $\begin{array}{l}0.05^{* * *} \\
0.29 * * * \\
-0.05\end{array}$ \\
\hline $\begin{array}{l}\text { Fetuses with } \\
\text { digoxin } \\
\text { therapy } \\
\qquad \mathrm{N}=20\end{array}$ & $\begin{array}{l}\text { TD } \\
\text { DELFIA } \\
\text { AMERLITE } \\
\text { TD } \\
\text { after ultrafiltration }\end{array}$ & $\begin{array}{c}0.249^{*} \\
0.375^{*} \\
0.006 \\
-0.055\end{array}$ & $\begin{array}{l}0.981 \\
1.000 \\
1.027 \\
1.058\end{array}$ & $\begin{array}{l}0.952 \\
0.923 \\
0.983 \\
0.988\end{array}$ & & $\begin{array}{l}0.26^{* * *} \\
0.32 * * * \\
0.03 \\
0.00\end{array}$ \\
\hline
\end{tabular}

* The hypothesis $\mathrm{a}=0$ is rejected $(\mathrm{p}<0.05)$

** The hypothesis $b=1$ is rejected $(\mathrm{p}<0.05)$

*** The hypothesis $d=0$ is rejected $(\mathrm{p}<0.05)$

$\triangle$ For all values of $\mathrm{r}: \mathrm{p}<0.01$

Tab. 6. Statistical evaluation of the analytical results with the $\mathrm{TD}_{\mathrm{X}}$ method before and after ultrafiltration $(\mathrm{a}=$ point of intersection of the axis, $b=$ slope of the regression line, $r=$ correlation coefficient; $d=$ difference between the average analytical values after and before ultrafiltration).

\begin{tabular}{lllll}
\hline Patient & $\mathrm{a}$ & $\mathrm{b}$ & $\mathrm{r}$ & $\mathrm{d}$ \\
\hline $\begin{array}{l}\text { Non pregnant women with digoxin therapy } \\
\mathrm{N}=35\end{array}$ & -0.083 & 1.031 & 0.988 & 0.00 \\
$\begin{array}{l}\text { Pregnant women with digoxin therapy } \\
\mathrm{N}=26\end{array}$ & -0.075 & 0.972 & 0.965 & $-0.18^{* * *}$ \\
$\begin{array}{l}\text { Fetuses with digoxin therapy } \\
\mathrm{N}=30\end{array}$ & $-0.293^{*}$ & 1.037 & 0.961 & $-0.26^{* * *}$ \\
\end{tabular}

\footnotetext{
* The hypothesis $\mathrm{a}=0$ is rejected $(\mathrm{p}<0.05)$

*** The hypothesis $d=0$ is rejected $(p<0.05)$

$\triangle$ For all values of $r: p<0.01$
}

Figure $5(\mathrm{a}-\mathrm{c})$ and figure 6 show the results of measurements in blood from fetuses receiving digoxin medication.

Statistics for the comparison of each method with the radioimmunoassay (used here as the "reference method") (figs 1, 3 and 5) are given in table 5. The corresponding data for the comparison before and after ultrafiltration are given in table 6 .

\section{Discussion}

Endogenous, digoxin-like immunoreactive factors (DLIF) are substances in plasma (or serum), which react with antibodies against digoxin. These factors are found in patients with liver and kidney diseases, but they are especially prevalent in pregnant women and newborn infants. Their identification and quan- titative determination would be of considerable physiological and methodological interest, as well as enabling an improvement of the accuracy of immunological digoxin determination $(10-12)$.

In patients receiving digoxin therapy, cardio-inactive metabolites of digoxin can react in the immunoassay, resulting in erroneously high apparent digoxin concentrations $(23-25)$. The "digoxin-like immunoreactive factors" in patients not receiving digoxin therapy have so far been characterized only superficially; the findings are often speculative and contradictory (26, 27).

"Digoxin-like immunoreactive factors" can be subdivided into two groups: factors which only react with antibodies against digoxin, and those which also inhibit the Na,K-ATPase, thereby possibly playing a role in the regulation of blood. pressure (for review 
see 1. c. (28)). Fatty acids $(27,29)$, phospholipids $(27$, $30)$, steroids (31), and bile acids $(32,33)$ have all been suggested as "digoxin-like immunoreactive factors", with varying degrees of probability. "Digoxin-like immunoreactive factors" certainly represent a heterogeneous group of substances, with certain common properties and characteristics, i.e. water solubility, heat stability, resistance to proteolytic enzymes and a relative molecular mass $M_{\mathrm{r}}<1000$ (34).

Difficulties and contradictions in the investigation of "digoxin-like immunoreactive factors" are due in no small part to the methodological problems that they cause in the quantitative determination of digoxin, and the fact that the magnitude of their interference in the digoxin assay depends on the radioimmunoassay used (35). Even high-performance liquid chromatography (HPLC) or a combination of HPLC with an immunoassay has so far not resulted in a reference method $(23,24,36,37)$.

In the present work, four immunochemical methods for the determination of digoxin are compared, which differ principally in their detection systems. A "classical" competitive radioimmunoassay was investigated, together with a fluorescence polarization immunoassay (Abbott $\mathrm{TD}_{\mathrm{X}}$ ), a time-resolved fluoroimmunoassay (DELFIA) and a luminescence-amplified enzyme-immunoassay (AMERLITE).

RIA, TD $_{x}$ and AMERLITE show similar values for precision in series. Day to day precision is also very similar for the three methods, the RIA showing only a slightly greater scatter than the $\mathrm{TD}_{\mathrm{X}}$ and AMERLITE methods (tab. 1). The largest variation coefficients, both in series and from day to day, were found for the DELFIA method. So far, the only published detailed studies of the DELFIA digoxin assay are those of the manufacturer (38), who reported variation coefficients much lower than those found in the present work.

For the comparison of methods, an established RIA was used as the reference method. According to the literature $(13,21,22)$, this method employs highly specific anti-digoxin antibodies, and it is only slightly influenced by "digoxin-like immunoreactive factors".

In the analysis of 57 sera from non-pregnant women receiving digoxin, the results from the $\mathrm{TD}_{\mathbf{x}}$ showed the closest correspondence (i. e. the smallest differences) with those from the RIA (fig. 1a, tab. 5); the difference of $0.09 \mathrm{nmol} / 1$ between the average values from the two assays is not significantly different from zero. On the other hand, the results from AMERLITE and DELFIA differed significantly $(0.21 \mathrm{nmol} / 1$ and $0.31 \mathrm{nmol} / 1$, respectively) from the RIA results.
Various reasons for these differences can be deduced from the statistical data for the regression functions (tab. '5): the differences between the RIA and AMERLITE results can be essentially explained by different standardization procedures $(b \neq 1)$, whereas DELFIA shows systematic differences over the entire analytical range $(a \neq 0)$. It is noticeable that the $T D_{x}$ values are higher than the RIA values in the lower analytical range, and lower in the upper analytical range.

The binding of both "digoxin-like immunoreactive factors" and digoxin to protein is markedly temperature-dependent $(34,39)$. At $37^{\circ} \mathrm{C}, 20-25 \%$ of digoxin is bound to plasma proteins, but only about $5 \%$ is bound at $4{ }^{\circ} \mathrm{C}$. Most of the "digoxin-like immunoreactive factors" appear to be bound to plasma proteins, and the binding decreases at higher temperatures. Ultrafiltration of serum at $2-4^{\circ} \mathrm{C}$ should therefore remove most (16) or all (17) of the "digoxinlike immunoreactive factors" without loss of digoxin. Since this procedure has so far been tried on only a few samples, 35 serum samples from non-pregnant patients under digoxin therapy were analysed with $\mathrm{TD}_{\mathbf{x}}$ before and after ultrafiltration.

Figure 2 and table 6 show that under these conditions the recovery of digoxin is $100 \%$.

In the analysis of 50 samples from healthy pregnant women not receiving digoxin, the results showed a marked dependency on the method (tab. 2). "Digoxinlike immunoreactive factors" were detected in all samples with $\mathrm{TD}_{\mathrm{X}}$, in $42 \%$ of samples with DELFIA, and in only $18 \%$ of samples with AMERLITE. However, the RIA was also influenced by "digoxin-like immunoreactive factors" with surprisingly high frequency (22\%).

From the individual values of the above analyses it is clear that the results are influenced by the different specificities of the various antibodies. Depending on the analytical method, the highest values for "digoxinlike immunoreactive factors" were found in different sera. Thus, the sample containing the highest value when analysed with $\operatorname{TD}_{\mathrm{x}}(0.54 \mathrm{nmol} / \mathrm{l})$, gave a value of $0.13 \mathrm{nmol} / \mathrm{l}$ with AMERLITE and $<0.01 \mathrm{nmol} / \mathrm{l}$ with RIA and DELFIA. The highest concentration recorded with RIA $(0.20 \mathrm{nmol} / \mathrm{l})$ was recorded as 0.32 $\mathrm{nmol} / \mathrm{l}$ with $\mathrm{TD}_{\mathrm{X}}, 0.35 \mathrm{nmol} / \mathrm{l}$ with DELFIA and 0.07 nmol/l with AMERLITE.

The TD $\mathrm{X}^{-}$and DELFIA-values show no correlation $(r=0.011)$, while a weak correlation exists between the $\mathrm{TD}_{\mathrm{x}^{-}}$and AMERLITE-values $(\mathrm{r}=0.316)$. From this it can be concluded that, at least in the case of TD $x$ and DELFIA, the substances acting as "digoxinlike immunoreactive factors" are different. 
Ultrafiltration is very effective for the elimination of "digoxin-like immunoreactive factors". Christenson (17) found no "digoxin-like immunoreactive factors" in 17 ultrafiltered pregnancy sera, whereas our own studies showed a $90 \%$ decrease of "digoxin-like immunoreactive factors", in agreement with the results of Graves et al. (16).

Much higher concentrations of "digoxin-like immunoreactive factors" are found in the umbilical cord blood and in the blood of untreated fetuses (tab. 3). Here also, the results are markedly method-dependent: "Digoxin-like immunoreactive factors" were found in only $8 \%$ of samples with RIA, whereas the non-radioactive methods detected "digoxin-like immunoreactive factors" in $100 \%$ (or $98 \%$ ) of the samples. The highest concentrations were found with $\mathrm{TD}_{\mathrm{X}}$ and DELFIA, but here again comparison of the individual values reveals only a weak correlation $(r=0.133)$ between the two methods. The high specificity of the RIA is especially evident from the analyses of umbilical and fetal blood samples. We cannot, however, confirm the statement by the AMERLITE manufacturer that the influence of "digoxin-like immunoreactive factors" on this assay is "relatively small or non-existent".

Ultrafiltration also efficiently removes "digoxin-like immunoreactive factors" from fetal and umbilical blood, the concentrations being reduced on average by $92 \%$.

Amniotic fluid, which consists largely of fetal urine, contains (depending of the analytical method) relatively high concentrations of "digoxin-like immunoreactive factors" (tab. 4). Ultrafiltration is not effective in the removal of "digoxin-like immunoreactive factors" from amniotic fluid, because the latter contains only a low concentration of protein.

No systematic studies have so far been published on the determination of digoxin in sera from pregnant women treated with digitalis preparations, or in the sera of digoxin-treated fetuses.

We investigated 40 sera from pregnant women treated with digitalis for fetal tachyarrhythmia. The results are shown in figure $3(\mathrm{a}-\mathrm{c})$ and table 5 . In addition, the samples were ultrafiltered and analysed by the fluorescence-polarization-immunoassay (fig. 4, tab. 6).

Based on the assumption that also under digitalis therapy, $90 \%$ of the "digoxin-like immunoreactive factors" in pregnancy serum can be eliminated by ultrafiltration, the average "digoxin-like immunoreactive factors" concentration of $0.18 \mathrm{nmol} / 1$ removed by ultrafiltration (tab. 6) corresponds exactly to the average concentration of $0.2 \mathrm{nmol} / 1$ in the serum of non-treated pregnant women (tab. 2). The maximal concentrations are also practically identical (fig. 4, tab. 2).

However, a different relationship is found between the results of the RIA and the thiree non-radioactive methods.

Thus, compared with the systematic differences between RIA and TD , or between RIA and DELFIA for the analysis of non-pregnancy serum (fig. $1(a-b)$, tab. 5) even greater differences would be anticipated for the analysis of pregnancy serum, because $\mathrm{TD}_{\mathbf{X}}$ and DELFIA are more influenced by "digoxin-like immunoreactive factors" than is the RIA (tab. 2). This is not apparent from the graphical presentation of the individual data (fig. $3(a-b)$ ), or from the statistical evaluation. The average differences between RIA and TD , or between RIA and DELFIA become smaller (TD ${ }_{\mathrm{X}}$ : 0.09/0.06 nmol/1; DELFIA: 0.31/0.29 $\mathrm{nmol} / \mathrm{l})$, rather than increasing by $0.11 \mathrm{nmol} / \mathrm{l}$ as expected.

We conclude from this that the composition of the "digoxin-like immunoreactive factors" changes in pregnancy under digoxin therapy, and that the RIA is particularly affected by this changed "digoxin-like immunoreactive factors". This theory is supported by comparison of the results from RIA and AMERLITE (fig. 3c). In non-pregnant women, the AMERLITE values were on average $0.21 \mathrm{nmol} / \mathrm{l}$ higher than the RIA values, whereas they were $0.05 \mathrm{nmol} / 1$ lower in sera from pregnant women treated with digitalis, despite the fact that both methods are influenced in identical fashion by the "digoxin-like immunoreactive factors" in non-pregnancy sera.

The results from the analysis of sera from digoxintreated fetuses were especially surprising.

In 30 samples measured with $\mathrm{TD}_{\mathrm{x}}$ before and after ultrafiltration, the average eliminated digoxin concentration was $0.26 \mathrm{nmol} / 1$ (range: $0.07-0.44 \mathrm{nmol} / \mathrm{l}$ ) (fig. 6, tab. 6). Assuming that $90 \%$ of "digoxin-like immunoreactive factors" are eliminated by ultrafiltration, comparison with the results in table 3 indicates. that the average concentration of "digoxin-like immunoreactive factors" in the blood of treated fetuses is only $46 \%$ of that in untreated fetuses.

The RIA and AMERLITE values are not significantly different from the $\mathrm{TD}_{\mathrm{x}}$ values after ultrafiltration (tab. 5). Before ultrafiltration, however, the values obtained with $\mathrm{TD}_{\mathrm{X}}$ and with DELFIÂ are markedly higher than the RIA values (fig. 5). Thus, under digoxin therapy, fetal blood also contains an altered population of "digoxin-like immunnoreactive factors", which affect the various assays in different ways. 
The observed decrease of the concentration of "digoxin-like immunoreactive factors" in fetuses under digoxin therapy appears to contradict the results of Weiner et al. (40), which are just the opposite of ours. These authors, however, could not differentiate analytically between digoxin and "digoxin-like immunoreactive factors", so that their high "DLIF" concentration in the serum of treated fetuses may well be explained by the transfer of digoxin across the placenta.

In a recently published study (41), Paci et al. reported the presence of specific receptors for digoxin on the placental membrane; "digoxin-like immunoreactive factors" are especially tightly bound by these receptors, thereby inhibiting the binding of digoxin.

The majority of the treated pregnant women in our collective, ultrasonography showed a hydropic placenta, which was up to twice the size of a normal placenta. It seems possible that the number of receptors is increased in hydropic placentas, which would explain the decrease in the concentration of "digoxinlike immunoreactive factors".

\section{Conclusions}

1. The varying sensitivity to "digoxin-like immunoreactive factors" already described for various radioimmunoassays is also displayed by the non-radioactive methods investigated in the present work. The greatest sensitivity to "digoxin-like immunoreactive factors" in pregnancy serum is shown by the $T D_{x}$ method, followed by DELFIA, RIA, AMERLITE and finally by $\mathrm{TD}_{\mathrm{X}}$ for the analysis of the ultrafiltrate.
For fetal and umbilical blood, the order is $\mathrm{TD}_{\mathrm{x}} \rightarrow$ DELFIA $\rightarrow$ AMERLITE $\rightarrow$ RIA $\rightarrow$ TD $_{x}$ (ultrafiltrate). Concentrations of "digoxin-like immunoreactive factors" vary greatly over a wide range, and it is therefore not possible to correct analytical results by subtracting a constant value for this unspecific interference.

2. Digoxin therapy during pregnancy alters the spectrum of "digoxin-like immunoreactive factors", which affects the sensitivity of the assay (especially the RIA) to "digoxin-like immunoreactive factors". The lowest values for "digoxin-like immunoreactive factors" are found in ultrafiltered samples, using the $\mathrm{TD}_{\mathrm{x}}$ method. This latter method, and not the RIA, can therefore be recommended as the method with the highest specificity.

3. Under digoxin therapy, the concentration of "digoxin-like immunoreactive factors" in fetal blood is decreased to about half of that in untreated fetuses.

The most plausible results are obtained by analysis of the ultrafiltered serum from fetuses undergoing digoxin therapy with the $\mathrm{TD}_{\mathbf{X}}$ method; however, RIA and AMERLITE give practically identical results.

4. Owing to its poor precision and high sensitivity to "digoxin-like immunoreactive factors", the DELFIA method is the least suitable for the monitoring of digoxin therapy in maternal and fetal blood.

5. Measurement of digoxin with the fluorescencepolarization-immunoassay after ultrafiltration of the serum sample yields the most accurate results. With this method, the requirement for a quick analysis of a single sample can also be met.

\section{References}

1. Klein, A. M., Holzmann, J. R. \& Austin, E. M. (1979) Fetal tachycardia before the development of hydrops-attempted pharmacologic cardioversion. Am. J. Obstet. Gynecol. 124, 347-348.

2. Lingman, G., Ohrlander, S. \& Ohlin, P. (1980) Intrauterine digoxin treatment of fetal paroxysmal tachycardia. Case report. Br. J. Obstet. Gynaecol. 87, 340-342.

3. Kerenyi, T. D., Meller, J., Steinfeld, L., Gleicher, N., Brown, E., Chitkara, U. \& Raucher, H. (1980) Transplacental cardioversion of intrauterine supraventricular tachycardia with digitalis. Lancet $1,393-394$.

4. Kleinman, C. S., Copel, J. A., Weinstein, E. M., Santulli, T. V. \& Hobbins, J. C. (1985) In utero treatment of fetal supraventricular tachycardia. Semin. Perinatol. 9, 113129.

5. Gembruch, U., Hansmann, M., Redel, D. A. \& Bald, R. (1987) Antiarrhythmische Direktbehandlung des Feten zur Kardioversion fetaler Tachyarrhythmien. Ultraschall Klin. Prax. 2, 33-40.

6. Gembruch, U., Hansmann, M., Redel, D. A. \& Bald, R (1988) Intrauterine therapy of fetal tachyarrhythmias; Intraperitoneal administration of antiarrhythmic drugs to the fetus in fetal tachyarrhythmias with severe hydrops fetalis. J. Perinat. Med. 16, 39-44.

7. Mimura, S., Suzuki, C. \& Yamazak, T. (1987) Transplacental passage of digoxin in a case of nonimmune hydrops fetalis. Clin. Cardiol. 10, 63-65.

8. Gembruch, U., Manz, M., Bald, R., Rüddel, H., Redel, D. A., Schlebusch, H., Nitsch, J. \& Hansmann, M. (1989) Repeated intravascular treatment with amidarone in a fetus with refractory supraventricular tachycardia and hydrops fetalis. Am. Heart J. 118, 1335-1338.

9. De Lia, J. E., Emery, M. G., Sheator, S. A. \& Jennison, T. A. (1985) Twin transfusion syndrome: successful in utero treatment with digoxin. Int. J. Gynaecol. Obstet. 23, 197201.

10. Valdes, R. (1985) Endogenous digoxin-like immunreactive factors: Impact on digoxin measurements and potential physiological implications. Clin. Chem. 31, 1525-1532. 
11. Soldin, S. J. (1986) Digoxin - Issues and controversies (Review). Clin. Chem. 32, 5-12.

12. Stonc, J. A. \& Soldin, S. J. (1989) An update on digoxin (Reviev). Clin. Chem. 35, 1326-1331.

13. Hicks. J. M. \& Brett, E. M. (1984) Falsely increased digoxin concentrations in samples from neonates and infants. Ther. Drug Monit. 6, 461-464.

14. Graves, S. W., Valdes, R., Brown, B. A., Knight, A. B. \& Craig, H. R. (1984) Endogenous digoxin-immunreactive substances in human pregnancies. J. Clin. Endocrinol. Metab. $58,748-751$.

15. Daffos, F., Capella-Pavlovsky, M. \& Forestier, F. (1985) Fetal blood sampling during pregnancy with the use of a needle guided ultrasound: a study of 606 consecutive cases. Am. J. Obstet. Gynecol 153, 665-670.

16. Graves, F. W., Sharma, K. \& Chandler, A. B. (1986) Methods for eliminating interferences in digoxin immunoassays caused by digoxin-like factors. Clin. Chem. 32, 1506-1509.

17. Christenson, R. H., Studenberg, S. D., Beck-Davis, S. \& Sedor, F. A. (1987) Digoxin-like immunoreactivity eliminated from serum by centrifugal ultrafiltration before fluorescence polarization immunoassay of digoxin. Clin. Chem. 33, 606-608.

18. Borth, R. (1970) Theoretical aspect of saturation analysis. Acta Endocrinol. 64 (Suppl. 147), 32-33.

19. Seth, J. (1990) Estimation of sensitivity of immunoassays (Letter). Clin. Chem. 36, 178.

20. Passing, H: \& Bablok, W. (1983) A new biometrical procedure for testing the equality of measurements from two different analytical methods. J. Clin. Chem. Clin. Biochem. 21, 709-720.

21. Gortner, L. \& Hellenbrecht, D. (1985) An RIA-Kit that is more specific for digoxin in serum of newborns (letter). Clin. Chem. 31, 155.

22. Mc Carthy, R. C. (1985) Minimizing the effect of digoxinlike immunreactive substances in immunoassays for digoxin in neonatal sera (letter). Clin. Chem. 31, 1240-1241.

23. Gault, M. H., Longerich, L., Dawe, M. \& Vasdev, S. (1985) Combined liquid chromatography/radioimmunoassay with improved specificity for serum digoxin. Clin. Chem. 31, $1272-1277$.

24. Longerich, L., Vasdev, S., Johnson, E. \& Gault, M. H. (1988) Disposable-column radioimmunoassay for serum digoxin with less interference from metabolites and endogenous digitalis-like factors. Clin. Chem. 34, 2211-2216.

25. Stone, J. A. \& Soldin, S. J. (1988) Improved liquid chromatographic/immunoassay of digoxin in serum. Clin. Chem. 34, 2547-2551.

26. Lau, B. W. C. \& Valdes, R. (1988) Criteria for identifying endogenous compounds as digoxin-like immunreactive factors in humans. Clin. Chem. Acta 175, 67-78.

27. Kelly, R. A., O'Hara, D. S., Mitch, W. E. \& Smith, T. W. (1986) Identification of NaK-ATPase inhibitors in human plasma as non esterified fatty acids and lysophospholipids. J. Biol. Chem. 261, 11704-11711.
28. Graves, S. W. \& Williams, G. H. (1987) Endogenous digitalis-like natriuretic factors (Review). Annu. Rev. Med. 38, $433-444$.

29. Tamura, M., Kuwano, H., Kinoshita, T. \& Inagami, T. (1985) Identification of linoleic and oleic acids as endogenous $\mathrm{Na}^{+}, \mathrm{K}^{+}$-ATPase inhibitors from acute volume-expanded hog plasma. J. Biol. Chem. 260, 9672-9677.

30. Hamlyn, J., Schienden, J., Zyren, J \& \& Baczynskyj, L. (1987) Purification and characterization of digitalis like factors from human plasma. Hypertension 10 (Suppl, I), 171-177.

31. Vasdev, S., Longerich, L., Johnson, E., Brent, D. \& Gault, M. H. (1985) Dehydroepiandrosterone sulfate as a digitalis like factor in plasma of healthy human adults. Res. Commun. Chem. Pathol. Pharmacol. 49, 387-399.

32. Vasdev, S., Longerich, L., Ittel, T. H., Johnson, E., Barrowman, J. A. \& Gault, M. H. (1986). Bile salts as endogenous digitalis like factors. Clin. Invest. Med. 9, 201-208.

33. Toseland, P. A., Oldfield, P. R., Murphy, G. M. \& Lawson, A. M. (1988) Tentative identification of a digoxin-like immunoreactive substance. Ther. Drug Monit. 10, 168-171.

34. Valdes, R. \& Graves, S. W. (1985) Protein binding of endogenous digoxin-immunoactive factor in human serum and its variation with clinical condition. J. Clin. Endocrinol. Metab. 60, 1135-1143.

35. Pudek, M. R., Seccombe, D. E., Jacobson, B. E. \& Whitfield, M. F. (1983) Seven different digoxin immunoassay kits compared with respect to interference by a digoxinlike immunoreactive substance in serum from premature and full-term infants. Clin. Chem. 29, 1972-1974.

36. Vetticaden, S. J., Barr, W. H. \& Beightol, L. A. (1986) Improved method for assaying digoxin in serum using highperformance liquid chromatography-radioimmunoassay. J. Chromatogr. 383, 187-193.

37. Jakobson, P. \& Waldorff, S. (1986) Determination of digoxin, digoxigenin and dihydrodigoxigenin in urine by extraction, derivatization and high-performance liquid chromatography. J. Chromatogr. 382, 349-354.

38. Helsingius, P., Hemmilä, I. \& Lövgren, T. (1986) Solidphase immunoassay of digoxin by measuring time-resolved fluorescence. Clin. Chem. 32, 1767-1769.

39. Lukas, D. S. \& de Martino, A. G. (1969) Binding of digitoxin and some related cardenolides to human plasma proteins. J. Clin. Invest. 48, $10141-10153$.

40. Weiner, C. P., Landas, S. \& Per̈soon, T. J. (1987) Digoxinlike immunoreactive substance in fetuses with and without cardiac pathology. Am. J. Obstet. Gynecol. 157, 368-371.

41. Paci, A., Cocci, F., Piras, F., Ciarimboli, G. \& Clerico, A. (1989) Specific binding of cardiac glycoside drugs and endogenous digitalis-like substances to particulate membrane fractions from human placenta. Clin. Chem. 35, 20932097.

Dr. H. Schlebusch

Klinisch-chemisches Laboratorium des Zentrums für Geburtshilfe und Frauenheilkunde der

Universität Bonn

Sigmund-Freud-Straße 25

W-5300 Bonn 1 